balloons. The team will be led by Dr. Marcel Stein, of the University. The balloon flights will be part of a project investigating cosmic rays in the region of $10,000 \mathrm{BeV}$. Large stacks of photographic sheet emulsion will be sent by unmanned 'Skyhook' balloons to an altitude of $120,000 \mathrm{ft}$. for a $24 \cdot \mathrm{hr}$. period. Pressurized, light-tight gondolas attached to the balloon will contain the stacks, each of which measures approximately $2 \mathrm{ft} . \times 1 \frac{1}{2} \mathrm{ft} . \times 1 \mathrm{ft}$. This is about five times the size of comparable film stacks which have previously been sent up. A particle from outer space, such as a proton, entering the stack collides with a heavy atomic nucleus in the emulsion and the resulting nuclear explosion generates a jet of very energetic particles. This jet, like a burst of particles in an accelerator, strikes other nuclear targets and produces a whole series of new nuclear reactions, all recorded on the emulsion stacks. The purpose of the study, which will continue for three years, is to investigate high-energy elementary nuclear particles which can only be observed at the high altitudes reached in balloon flights. Calculations show that the flights should yield a substantial number of collisions above $10,000 \mathrm{BeV}$. and as many as 30,000 interactions at the lower but still significant 100-BeV. energy level. Quantities to be measured by the experiment include: primary energies of nucleons, number of charged and neutral secondary particles, interaction mean free paths of secondary particles, cross-sections from primary and secondary interactions as a function of their energy, energy loss per collision of nucleons, angular and energy distribution of secondary particles as a function of primary energy, energy spectra of heavy nuclei, and break-up in the cosmic radiation.

\section{New Round-the-World Telephone Cable}

THE construction of a round-the-world Commonwealth telephone cable was considered at the Commonwealth Trade and Economic Conference in Montreal. It was envisaged that its provision would be based on capital contributions from all Commonwealth countries and that the new cable could be operated on a self-supporting financial basis. The first trans-oceanic telephone cable was opened in 1956 between the United Kingdom, Canada and the United States, and the construction of a further cable between Canada and the United Kingdom is expected to be completed in 1961. This would form the first part of the new Commonwealth link. The rest of the route considered by the experts would be as follows: the west coast of Canada would be linked with New Zealand and Australia, and from there the cable would run through the Indian Ocean connecting Malaya, India, Pakistan and Ceylon, and from these countries by way of Kenya to South Africa. By providing a link between South Africa and the United Kingdom, connexion would be made with trans-Atlantic telephone cables.

The order of construction must be a matter for further consideration by Commonwealth Governments, but it may be that the existing and proposed links from the United Kingdom to Canada would first be extended by a cable from the United Kingdom to South Africa and a cable across the Pacific to New Zealand and Australia; the links spanning the Indian Ocean, to be constructed later, would complete the girdle of the world. The conference estimated that the total length of a round-the-world telephone cable of this nature would be about 27,000 nautical miles, or nearly 30,000 nautical miles if the trans-
Atlantic crossing is included. The construction cost was estimated at $£ 88$ million, including the transAtlantic cables.

\section{Russian Scientific and Technological Literature}

Thanks to the co-operation of many organizations in Britain and abroad, the Department of Scientific and Industrial Research Lending Library Unit now has a growing collection of recent Russian scientific and technological literature. Despite its imperfections, it is already the largest in Western Europe. Lists of what Russian literature has been received are being issued, but the demand for this literature is not very great. It is clear that owing to the linguistic difficulties something more than the traditional library methods of making known what is available is required. Suggestions for new services will be considered. Whenever translations of Russian into English become available the Unit obtains copies if the cost of the translations is less than the actual cost of making new translations. Nevertheless, these measures by themselves appear to be inadequate, so it has been decided to initiate a translating programme. The basic idea behind the programme is that financial assistance should be available where necessary to help specialist organizations to select, translate and arrange for the publication of the important Soviet scientific and technical literature in their fields. This programme is being drawn up to avoid any duplication with the translating activities in the United States, and details about it will be made known later. Further information can be obtained from the Unit at 20 Chester Terrace, London, N.W.1.

\section{New 'Area of Outstanding Natural Beauty'}

THE Minister of Housing and Local Government, Mr. Henry Brooke, has confirmed an Order made by the National Parks Commission under the National Parks and Access to the Countryside Act, 1949, which has the effect of establishing about 26 square miles of countryside in Staffordshire, including Cannock Chase, as an 'area of outstanding natural beauty'. The area extends between Brocton, Tixall, Rugeley and Gentleshaw and also includes Shoal Hill Common to the south-west of Cannock Chase. Government grants can be made at the rate of 75 per cent towards the cost of treating derelict land, tree planting and preservation, and removing disfigurements. Grants are also available towards expenditure incurred in making agreements or orders for public access to open country and in appointing wardens. Designation does not of itself provide any additional right of access to private land. This is the sixth such area to be established. The others are : the Quantock Hills and Surrey Hills in the south of England, the Northumberland coast in the north, and the Gower and Lleyn Peninsulas in Wales.

\section{Corby Young Naturalists' Club}

CoRBY Young Naturalists' Club is now in its fourth year (School Nature Study, 53, No. 211 ; April 1958). It was formed first as a group of school children who liked rambles with someone who could identify and talk about the things they saw. From there it grew to a fully fledged club with meetings and a definite object to the rambles-a 'survey' of the local woods. Field work formed the basis of the Club. So many children were interested, and joined in the activities in their spare time, that it has been found necessary to work, not as a body, but in groups, 